\begin{tabular}{|c|c|c|}
\hline Case Reports in & \multicolumn{2}{|c|}{ Case Rep Gastroenterol 2019;13:305-309 } \\
\hline Gastroenterology & $\begin{array}{l}\text { DOI: 10.1159/000501067 } \\
\text { Published online: July 10, } 2019\end{array}$ & $\begin{array}{l}\text { (c) } 2019 \text { The Author(s) } \\
\text { Published by S. Karger AG, Basel } \\
\text { www.karger.com/crg }\end{array}$ \\
\hline & $\begin{array}{l}\text { This article is licensed under } \\
\text { International License (CC BY-^ } \\
\text { Usage and distribution for comn }\end{array}$ & $\begin{array}{l}\text { nons Attribution-NonCommercial } 4.0 \\
\text { ger.com/Services/OpenAccessLicense). } \\
\text { uires written permission. }\end{array}$ \\
\hline
\end{tabular}

\title{
Easy Detection and Fast Removal of Gastric Anisakis during Narrow-Band Imaging Endoscopy with L-Menthol Administration
}

\author{
Toshio Arai $^{a}$ Hiroki Yamada ${ }^{a}$ Takeya Edagawa $^{a}$ Hiromu Sugiyama $^{b}$ \\ Kenichirou Nakachi ${ }^{\mathrm{a}}$ \\ aDepartment of Gastroenterology, Hashimoto Municipal Hospital, Hashimoto, Japan; \\ ${ }^{b}$ Department of Parasitology, National Institute of Infectious Disease, Tokyo, Japan
}

\section{Keywords}

Anisakis $\cdot$ Narrow-band imaging $\cdot$ L-Menthol

\begin{abstract}
Anisakiasis is a parasitic disease caused by the ingestion of raw or uncooked seafood infected with third-stage larvae of the anisakid nematodes. A 45-year-old Japanese man presented with epigastric pain and itchy skin with rash on his arm, chest, and back after eating vinegar-marinated raw mackerel sushi. He underwent an emergent endoscopic examination using narrowband imaging (NBI) that revealed two anisakid larvae. NBI showed the larvae more clearly than white light imaging on the cardiac region of the stomach. We sprayed L-menthol on the larvae for stopping their movement and then easily removed them using biopsy forceps. The macroscopic examination and genotype analysis of the specimens revealed the two larvae as belonging to $A$. simplex sensu stricto. Our case demonstrates the usefulness of endoscopic examination with $\mathrm{NBI}$ and of the L-menthol spray in visualizing and immobilizing the larvae for removal.




\section{Case Reports in Gastroenterology}

Case Rep Gastroenterol 2019;13:305-309

DOI: 10.1159/000501067

www.karger.com/crg

Arai et al.: Easy Detection and Fast Removal of Gastric Anisakis during Narrow-Band Imaging Endoscopy with L-Menthol Administration

\section{Background}

Gastric anisakiasis is a parasitic disease acquired after ingesting raw or uncooked seafood harboring third-stage larvae of the nematodes belonging to the genus Anisakis or Pseudoteranova [1-4]. The disease is characterized by the acute onset of epigastric pain $1.4 \pm 1.1$ days after ingesting the contaminated food [1]. Anisakis larvae are reportedly killed by exposure to some medications such as peppermint, creosote, and albendazole in vitro in some animal models [5-7]. Although the clinical effectiveness of these medications after oral administration remains unclear, the endoscopic removal of the live larva from the gastric mucosa has been shown to cure the disease [1]. Precise diagnosis is obtained after endoscopic examination followed by morphological and genotype analysis of the removed larvae [1]. Thus, establishing the methods finding the larvae quickly and removing them thoroughly is crucial. Anisakis larva infection involves the invasion of the stomach by the larval head, and the entire larval body is often hidden among the gastric edematous folds. Additionally, the larva wiggles its body continuously and the tail moves quickly or even in circular motions [8, 9]. For these reasons, conventional endoscopic detection and removal of the living larvae remain challenging, and more sophisticated methods are required.

\section{Case Report}

A 45-year-old Japanese man with epigastric pain and itchy skin with rash of his arm, chest, and back reportedly ate vinegar-marinated raw mackerel sushi at a ramen restaurant $11 \mathrm{~h}$ prior to the development of the epigastric pain. His vital signs were normal. Physical examination showed moderate abdominal tenderness without rebound or guarding in the epigastrium.

On the basis of his clinical history and physical examination, we suspected gastric anisakiasis and performed an emergency endoscopic examination. We used a GIF-H290Z (Olympus Medical Systems) endoscopic apparatus and detected two white larvae penetrating into the thick mucosa of the cardiac part of the stomach. However, this identification was particularly challenging with white light imaging (WLI) because the surrounding mucosa was edematous and erythematous (Fig. 1a). Using narrow-band imaging (NBI) technology (structure enhancement function B8), the larvae were emphasized and contrasted clearly against the mucosal layers. We identified two larvae measuring approximately $15 \mathrm{~mm}$ in length. We could see the movement of the tails of the larvae during the procedure (Fig. 1b).

For inhibiting gastrointestinal spasms and weakening the larval movements, we sprayed L-menthol (MINCLEA, Nihon Seiyaku, Tokyo, Japan) onto both larvae on site. After the spray, the larval movements got weaker and they changed their shape from circles to straight lines in approximately $10 \mathrm{~s}$ (Fig. 1c, d). We were then able to easily catch the head portions of the larvae using endoscopic forceps (Fig. 1e). After the removal of the larvae, we verified the absence of remnants of the larvae in the stomach (Fig. 1f). After the procedure, the patient's symptoms completely and immediately resolved.

Morphological examination revealed the two larvae as being in the third-stage of $A$. simplex (Fig. 2). For verifying the species, we performed molecular analyses of the removed specimens by sequencing and confirmed them as $A$. simplex sensu stricto. 


\section{Discussion}

Gastric anisakiasis is a well-known parasitic disease resulting from the consumption of raw marine food infected with third-stage larvae of the nematode A. simplex, which causes severe epigastric pain and allergic reactions [5]. Although most patients with gastric anisakiasis are reportedly from Japan, due to the traditional Japanese habit of eating raw seafood (sashimi and sushi), the popularization of the food to other world regions has increased the number of patients of gastric anisakiasis globally [1].

The advanced NBI system depends on the use of two short-wavelength light beams of 415 $\mathrm{nm}$ (blue) and $540 \mathrm{~nm}$ (green) that are well absorbed by hemoglobin and applied optic digital methods for enhancing the images. The system improves visualization of the mucosal surface architecture and the microvascular patterns [10-12]. We used this NBI for enhancing the contrast between the small Anisakis larvae and the gastric mucosa, effectively facilitating the detection and the removal of the gastric Anisakis larvae [8].

L-Menthol is a peppermint oil solution compound that relaxes the gastrointestinal smooth muscle by reducing the calcium influx [13]. L-Menthol is reportedly effective as an antispasmodic drug during gastroendoscopic examinations $[14,15]$. The intraluminal administration of L-menthol using a hand pump is safe and simple. A limited number of clinical case studies reporting effective drugs against anisakiasis have included $L$-menthol as a candidate drug and provided its in vitro and in vivo experimental results against $A$. simplex [6]. We evidenced an effect of the L-menthol spray on the movement of the larvae and not just on the gastrointestinal smooth muscle of the patient [16]. Thus, our two-step strategy of NBI application for the easy detection of gastric Anisakis and spray injection of L-menthol for weakening the movement of the parasite worked in a complemental manner for facilitating larvae removal from the stomach with forceps. Thus, our method prevents accidental overlooking of the penetrating site of the Anisakis parasite on the gastric mucosal surface and allows for the safe and easy removal of the gastric Anisakis larvae. Future studies are required for confirming the efficacy of this method.

\section{Acknowledgement}

We thank Dr. Shunji Maekura and his staff, Department of Pathology, Hashimoto Municipal Hospital for useful discussions. We also thank Dr. Yoko Kato, Heart and Vascular Institute, Johns Hopkins University for reviewing this case report.

\section{Statement of Ethics}

There are no ethical conflicts to declare. We received written consent by the patient.

\section{Disclosure Statement}

The authors declare that there is no conflict of interest regarding the publication of this paper. 


\section{Case Reports in Gastroenterology}

\begin{tabular}{l|l}
\hline DOI: 10.1159/000501067 & (c) 2019 The Author(s). Published by S. Karger AG, Basel \\
\hline
\end{tabular} www.karger.com/crg

Arai et al.: Easy Detection and Fast Removal of Gastric Anisakis during Narrow-Band Imaging Endoscopy with L-Menthol Administration

\section{References}

1 Arai T, Akao N, Seki T, Kumagai T, Ishikawa H, Ohta N, et al. Molecular genotyping of anisakis larvae in Middle Eastern Japan and endoscopic evidence for preferential penetration of normal over atrophic mucosa. PLoS One. 2014 Feb;9(2):e89188.

2 Tokiwa T, Kobayashi Y, Ike K, Morishima Y, Sugiyama H. Detection of anisakid larvae in marinated mackerel sushi in Tokyo, Japan. Jpn J Infect Dis. 2018 Jan;71(1):88-9.

3 Zanelli M, Ragazzi M, Fiorino S, Foroni M, Cecinato P, Del Mar Jordana Sanchez M, et al. An Italian case of intestinal anisakiasis with a presurgical diagnosis: could this parasite represent an emerging disease? Pathol Res Pract. 2017 May;213(5):558-64.

4 del Carmen Romero M, Valero A, Navarro-Moll MC, Martín-Sánchez J. Experimental comparison of pathogenic potential of two sibling species Anisakis simplex s.s. and Anisakis pegreffii in Wistar rat. Trop Med Int Health. 2013 Aug;18(8):979-84.

5 Toyoda H, Tanaka K. Intestinal Anisakiasis Treated Successfully with Prednisolone and Olopatadine Hydrochloride. Case Rep Gastroenterol. 2016 May;10(1):30-5.

6 Romero MC, Navarro MC, Martín-Sánchez J, Valero A. Peppermint (Mentha piperita) and albendazole against anisakiasis in an animal model. Trop Med Int Health. 2014 Dec;19(12):1430-6.

7 Sekimoto M, Nagano H, Fujiwara Y, Watanabe T, Katsu K, Doki Y, et al. Two cases of gastric Anisakiasis for which oral administration of a medicine containing wood creosote (Seirogan) was effective. Hepatogastroenterology. 2011 Jul-Aug;58(109):1252-4.

8 Taranto D, Sessa G, Tortora R, Tremolaterra F. Narrow band imaging enhancement could improve gastric anisakis detection. Dig Liver Dis. 2011 Mar;43(3):e5.

9 Shiina M. Shigehiro Kokubo Experience of alimentary canal anisakiasis and use of l-menthol for removal of larvae Progress off. Dig Endosc. 2015;87:2017-25.

10 Ishihara R. Narrow Band Imaging for Diagnosis and Prediction of Infiltration Depth of Esophageal Neoplasias. Video J. Encycl. GI Endosc; 2013. pp. 90-1.

11 Zheng C, Lv Y, Zhong Q, Wang R, Jiang Q. Narrow band imaging diagnosis of bladder cancer: systematic review and meta-analysis. BJU Int. 2012 Dec;110(11b 11 Pt B):E680-7.

12 Ezoe Y, Muto M, Uedo N, Doyama H, Yao K, Oda I, et al. Magnifying narrowband imaging is more accurate than conventional white-light imaging in diagnosis of gastric mucosal cancer. Gastroenterology. 2011 Dec;141(6):2017-2025.e3.

13 Hills JM, Aaronson PI. The mechanism of action of peppermint oil on gastrointestinal smooth muscle. An analysis using patch clamp electrophysiology and isolated tissue pharmacology in rabbit and guinea pig. Gastroenterology. 1991 Jul;101(1):55-65.

14 Hiki N, Kaminishi M, Yasuda K, Uedo N, Honjo H, Matsuhashi N, et al. Antiperistaltic effect and safety of Lmenthol sprayed on the gastric mucosa for upper GI endoscopy: a phase III, multicenter, randomized, double-blind, placebo-controlled study. Gastrointest Endosc. 2011 May;73(5):932-41.

15 Hiki N, Kurosaka H, Tatsutomi Y, Shimoyama S, Tsuji E, Kojima J, et al. Peppermint oil reduces gastric spasm during upper endoscopy: a randomized, double-blind, double-dummy controlled trial. Gastrointest Endosc. 2003 Apr;57(4):475-82.

16 Kroeger M, Karl H, Simmler B, Singer P. Viability Test Device for anisakid nematodes. Heliyon. 2018 Mar;4(3):e00552. 


\section{Case Reports in Gastroenterology}

\begin{tabular}{l|l}
\hline Case Rep Gastroenterol 2019;13:305-309 \\
\hline DOI: 10.1159/000501067 & $\begin{array}{l}\text { ( ) 2019 The Author(s). Published by S. Karger AG, Basel } \\
\text { www.karger.com/crg }\end{array}$ \\
\hline
\end{tabular}

Arai et al.: Easy Detection and Fast Removal of Gastric Anisakis during Narrow-Band Imaging Endoscopy with L-Menthol Administration

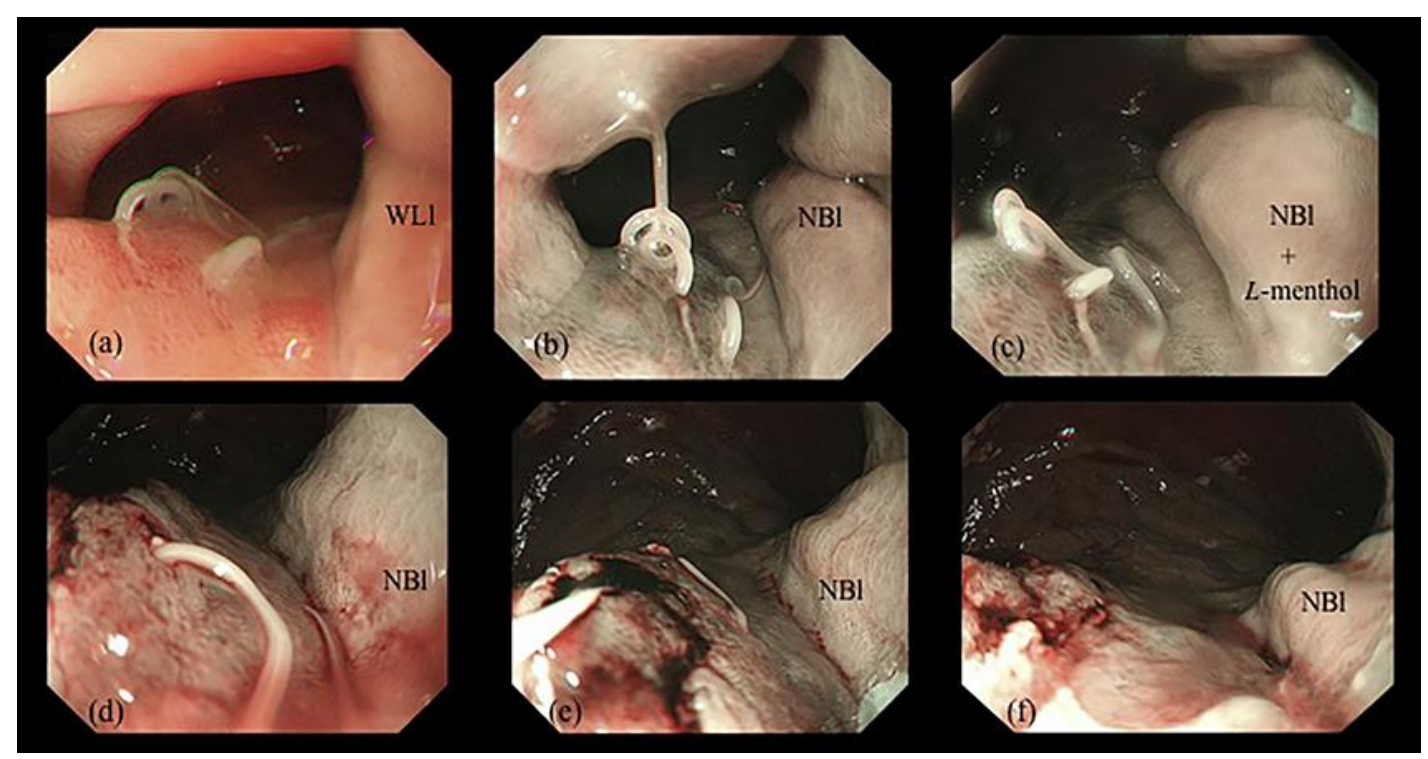

Fig. 1. Endoscopic image of the Anisakis simplex larvae. a Endoscopic image of the stomach demonstrating two larvae with white light imaging. The larvae are almost indistinguishable from the edematous and erythematous gastric mucosa. $\mathbf{b}$ Endoscopic image of the stomach with narrow-band imaging highlighting the larvae against the background of the gastric mucosa. c, $\mathbf{d}$ Endoscopic image of the A. simplex parasite after L-menthol spraying of the parasites. The larvae changed their shape from circular to straight lines. e Endoscopic image of the stomach demonstrating biopsy forceps removing the larvae. $f$ Endoscopic image of the stomach after larvae removal. No larvae remains were left on the stomach.

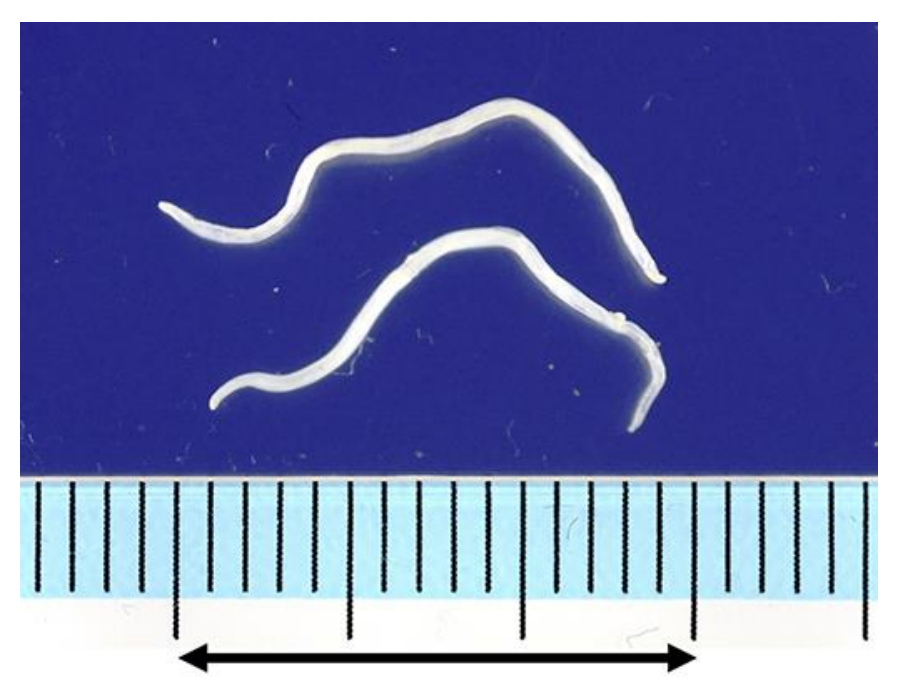

$15 \mathrm{~mm}$

Fig. 2. Morphological image of A. simplex. $15 \mathrm{~mm}$ white worms are consistent with $A$. simplex larvae. 